\title{
THE THIRD INTERNATIONAL CONFERENCE OF GOLD AND SILVER IN MEDICINE
}

The Third International Conference on Gold and Silver in Medicine will be held next summer in Milwaukee Wisconsin USA, August 18-20, 1994.

The site of the meeting will the University of Wisconsin, Milwaukee.

Accomodations will be available in student dormitories at UWM Sandburg Residence Hall and also at the Milwaukee Hilton Hotel.

Abstracts of Meeting talks will be published. The deadline for receipt is March 30, 1994.

Tentative registration fees have been set as $\$ 150$ for participants, $\$ 100$ for postdoctoral associates and $\$ 75$ for students. We hope to be able to provide some level of assistance, especially to students and travelers from outside North America.

The current list of invited speakers includes:

Richard Beard, Drexel University

Richard Elder, University of Cincinnati

Ernst Gleichman, Heinrich-Heine University, Dusseldorf

Colin Lock, McMaster University, Ontario, Canada

Peter Sadler, Birkbeck College, University of London, UK

Frank Shaw, University of Wisconsin-Milwaukee

Ewen Smith, Strathclyde University, Glascow, UK Martin Stillman, University of Western Ontario, Canada

Katherine Tepperman, University of Cincinnati

If you wish further information contact: "Richard.EIder @UC.EDU" via INTERNET or FAX (513) $\quad 556-9239$ or voice (513) 556-9200. 